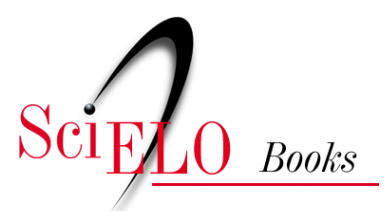

\title{
Uma História do Dr. Hairy Moussatché (outubro de 1988)
}

\author{
Virgínia Schall
}

\section{SciELO Books / SciELO Livros / SciELO Libros}

SCHALL, V. Uma História do Dr. Hairy Moussatché (outubro de 1988). In: Contos de Fatos: histórias de Manguinhos [online]. Rio de Janeiro: Editora FIOCRUZ, 2001, pp. 17-23. ISBN: 978-857541-614-3. Available from: doi: 10.7476/9788575416143.0004. Also available in ePUB from: http://books.scielo.org/id/hdq6f/epub/schall-9788575416143.epub.

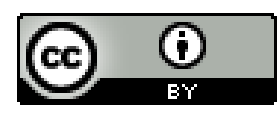

All the contents of this work, except where otherwise noted, is licensed under a Creative Commons Attribution $\underline{4.0 \text { International license. }}$

Todo o conteúdo deste trabalho, exceto quando houver ressalva, é publicado sob a licença Creative Commons Atribição 4.0. 


\section{Uma História do Dr. \\ Haity Moussatché \\ (outubro de 1988)}

Certamente os fatos existem, estão aí: o que ocorre éque muitas vezes não os vemos.

Charcot

G ncontrei Dr. Moussatché em sua sala, no Departamento de Farmacologia do Instituto Oswaldo Cruz (IOC), em 27 de outubro de 1988. Sob o jaleco antigo, de um branco alvo, sobressai a elegância do paletó e gravata, que se completa pela correntinha do relógio de ouro no bolso. A bengala descansa ao lado. O grande bigode branco é uma de suas marcas. De quando em quando, ele o cofia, absorto, gesto que persiste em minha memória. Os olhos são alegres, mantendo um brilho vivo enquanto fala; às vezes, denunciando o passeio ao passado. Nas paredes da sala, alguns pôsteres e fotos emolduradas; dentre elas, o rosto da Pietá de Michelangelo, a estátua Le Penseur, o retrato de Claude Bernard e de alguns colegas. Destacase o desenho do seu próprio rosto em crayon, ainda aos 50 anos. A semelhança com Einstein me desperta. Entre caixas, estantes, envelopes, livros e papéis, chama a atenção uma serpente no formol, em um grande tubo de vidro. Sobre a mesa, registro quatro frascos de Calcium Sandoz F e um livro intitulado Plantas e Substâncias Vegetais: tóxicas e medicinais. Retratos, objetos, livros, ali estão presentes os elementos da sua vida de pesquisa, indicando sua área de escolha e as temáticas de seu estudo. A arte, as pessoas queridas, o medicamento são outros sinais que falam de sua pessoa. 
Dr. Moussatché relata, com admiração pelo mestre, uma descoberta do Dr. Miguel Ozório de Almeida, com quem trabalhou por muitos anos. Destaca a importância do Dr. Miguel como um dos pioneiros da pesquisa em fisiologia no Brasil. Junto com seu irmão, Dr. Álvaro Ozório de Almeida, manteve por muitos anos um laboratório de fisiologia na própria casa dos pais, o qual atraiu muitos estudantes e outros profissionais. Após a morte de Oswaldo Cruz, quando o instituto passou a ser dirigido por Carlos Chagas, este convidou o Dr. Álvaro para montar na instituição um laboratório de fisiologia. Assim, em 1919, Dr. Álvaro recusou o convite, indicando seu irmão, Miguel, que aceitou trabalhar em Manguinhos, para onde levou parte do material de seu laboratório particular. O laboratório permitiu formar muitos outros profissionais, até ser desativado em 1932. Segundo Dr. Moussatché, Dr. Miguel foi um homem de vasta cultura, que participou de todo o movimento em prol do desenvolvimento da ciência no Brasil. Foi também um dos pioneiros na divulgação científica: sempre valorizou esta atividade e, ao exercê-la, buscava traduzir a ciência para a linguagem simples, tornando-a inteligível para a população. ${ }^{3}$

Mas vamos à história. Deixemos que o eco da voz do Dr. Moussatché se faça ouvir no ritmo e na forma em que foi possível registrar sua narrativa.

\section{Uma Descoberta Inesperada}

Itália, década de 30. O pesquisador brasileiro, assistido por curiosos colegas italianos que acompanhavam a montagem da experiência, ia ficando intrigado. Nada acontecia ao seu animal, uma rã italiana legítima, robusta e

\footnotetext{
${ }^{3} \mathrm{Em}$ A Dirulgação Cientifica no Rio de Janeiro: algumas reflexões sobre a década de 20, 1998. Dissertação de Mestrado, Rio de Janeiro: Instituto Brasileiro de Informação em C\&T (IBICT) e Escola de Comunicação da UFRJ, Luisa Massarani faz uma análise valiosa sobre o papel do Dr. Miguel Ozório de Almeida na divulgação científica no Brasil.
} 
saudável. A preparação perfeita, a medula e as patas do batráquio rigorosamente dissecadas e em posição estratégica. As soluções, minuciosamente preparadas com material da mais alta qualidade. $O$ banho para variar a temperatura do animal funcionava com precisão. Abaixou-se a temperatura até $8^{\circ} \mathrm{C}$, e nada aconteceu. A decepção do cientista foi total. Como poderia estar acontecendo tal fracasso? Afinal, tratava-se de um fenômeno descoberto por ele há algum tempo no Brasil e replicado inúmeras vezes por lá. A descoberta mudara o rumo de suas pesquisas. Até então, ele vinha estudando o efeito da temperatura sobre os reflexos, usando as rãs como modelo experimental. Reflexos são aquelas respostas automáticas, como o piscar de olhos em resposta imediata a uma luz que se acende subitamente, ou o dobrar da canela ao receber uma pancada no joelho, por exemplo. O procedimento de seus experimentos incluía preparar devidamente a rã, cuja cabeça era secionada. Conservavam-se apenas a medula e as patas dianteiras. A medula era mantida unida às patas dianteiras pelos dois nervos ciáticos. Aplicando-se alguns estímulos como frio ou calor na medula, podiam-se desencadear respostas reflexas. Tais experiências eram realizadas com o objetivo de conhecer os mistérios do funcionamento dos reflexos. O estímulo frio era possível por meio da variação da temperatura, utilizando-se um banho com soro fisiológico. Certa vez, ao aplicar uma temperatura de $8^{\circ} \mathrm{C}$, subitamente a rã exibiu uma convulsão epiléptica nas patas. Foi a primeira vez na história da fisiologia que um estímulo não tóxico provocava uma descarga epiléptica. Esse acontecimento reorientou as pesquisas do Dr. Miguel. Deixou de lado a pesquisa sobre os reflexos e passou a investigar a crioepilepsia, para melhor entender os mecanismos da origem das crises convulsivas produzidas em rãs por resfriamento da medula espinhal. A descoberta desse mecanismo patológico poderia trazer esclarecimentos sobre as crises epilépticas humanas.

Algum tempo depois o Dr. Miguel estava na Itália demonstrando a sua descoberta, a qual, repetida e misteriosamente, teimava em não funcionar. Mais uma vez, ele, com sua mente indagadora, levantou hipóteses e, depois 
de testes diversos, conseguiu encontrar uma explicação. Tratava-se de um fenômeno dependente da temperatura ambiente. Sendo a Itália um país com uma média de temperatura anual mais baixa do que o Brasil, só um estímulo de temperatura mais baixa provocaria a crise epiléptica nas rãs de lá. Assim, testando com rãs de diversos países e estados brasileiros, Dr. Miguel demonstrou que a temperatura variava para gerar o fenômeno de acordo com a média da temperatura ambiente. Por exemplo: em Recife, cuja temperatura média anual era de $26^{\circ} \mathrm{C}$, o resfriamento da rã a $12^{\circ} \mathrm{Cjá}$ provocava a crise. No Rio, de $23^{\circ} \mathrm{C}$ de temperatura média anual, obtinha-se a crise com um estímulo de $8^{\circ} \mathrm{C}$ e em Montevidéu, com $19^{\circ} \mathrm{C}$ de média, a crise só acontecia a $5^{\circ} \mathrm{C}$. Uma mesma espécie de rã na China, se encontrada em Pequim, com $11^{\circ} \mathrm{C}$ de média anual, não dava ataque com um resfriamento de até $0^{\circ} \mathrm{C}$. Já para as rãs de Cantão $\left(\operatorname{com} 23^{\circ} \mathrm{C}\right.$ de média anual), $\mathrm{o}$ ataque acontecia a $8^{\circ} \mathrm{C}$. Comprovou-se então que uma mesma espécie de rã muda o seu limite superior de acordo com o local de origem. Dr. Miguel ainda levantou hipóteses sobre a natureza do fenômeno, se adaptativo ou genético. Essa evidência gerou novas pesquisas, uma das quais em Cuba, onde rãs de origem canadense foram criadas por vinte anos. Supõe-se que exista então uma seleção filogenética do limite tér mico. Pois bem: de uma pesquisa orientada para estudar os reflexos, em dois momentos, em situações inesperadas, observam-se novos fenômenos - a crioepilepsia e a dependência da temperatura ambiente para a sua expressão em resposta ao estímulo - gerando novos conhecimentos e novas perguntas.

E Dr. Moussatché relatou muitos outros exemplos de ocorrências incidentais, como fatos que levaram à evidência de que o gambá resiste ao veneno de jararaca e ao entendimento de que uma fração protéica do seu soro se combina com o veneno e o desativa, pesquisa esta conduzida por ele próprio. Citou ainda a descoberta ocasional feita por Paul Ehrlich (18541915) no início do século, demonstrando por meio de estudos de corantes a presença dos grânulos no mastócito. Ehrlich é considerado o pai da moderna quimioterapia, tendo recebido o Prêmio Nobel em 1908 pelo 
desenvolvimento de uma droga para o tratamento da sífilis. E a descoberta de Lewin, sobre a mediação química dos nervos. Tentando provar a sua hipótese, Lewin sonhou com a experiência da prova, levantou, escreveu, mas esqueceu-se de pormenores da metodologia. Voltou a sonhar, reescreveu o sonho em detalhes e fez a experiência crucial, usando dois corações, demonstrando que a substância química passava de um para o outro. Em todos os exemplos, Dr. Moussatché destacou a importância destas circunstâncias favoráveis, ou 'causas exteriores', como define Einstein, para quem "a história das descobertas científicas e técnicas revela-nos que mesmo quando as condições exteriores e científicas para o aparecimento de uma idéia já existem há muito, será preciso, na maioria dos casos, uma outra causa exterior a fim de que chegue a se concretizar. O homem tem, no sentido literal das palavras, de se chocar contra o fato para que a solução lhe apareça".

$\mathrm{E}$ ao se chocar contra o fato, há que ter certas qualidades para percebê-lo e interpretá-lo. Aqui lembro um conto no qual Tchekhov, ao descrever o cientista-personagem, adverte: "em toda a sua vida, há de preparar algumas centenas de relatórios áridos, bem aceitáveis, fará uma dezena de traduções conscienciosas, mas não inventará a pólvora. Para a pólvora, é preciso ter imaginação, capacidade inventiva, espírito divinatório..." 


\section{Haity Moussatché ${ }^{4}$}

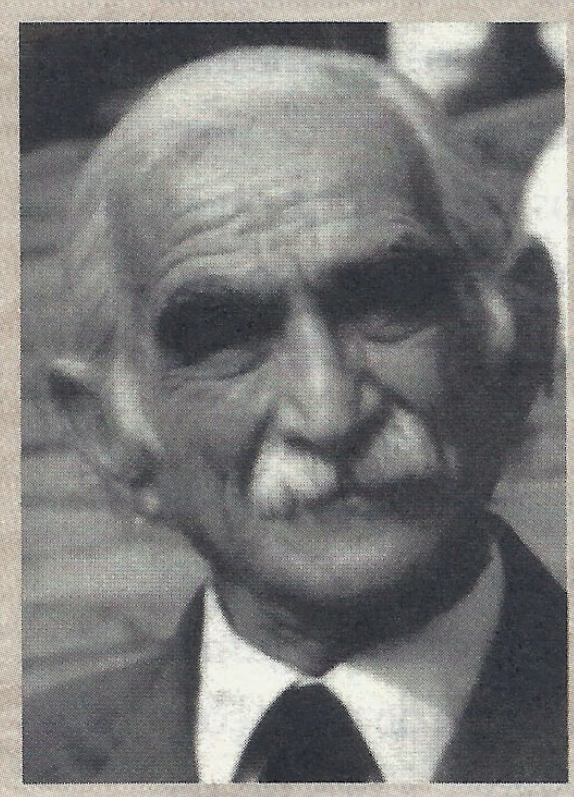

O cientista é um profissional essencialmente ético, porque a base da investigação científica é o respeito à verdade.

Dr. Haity Moussatché nasceu na Turquia, em 1910, e veio para o Brasil ainda criança. Formou-se em medicina no ano de 1933, na Universidade Federal do Rio de Janeiro, naquela época Universidade do Brasil. Trabalhou no $10 \mathrm{C}$ desde 0 tempo de estudante de medicina, tendo começado como monitor. Só anos depois, em 1937, veio a ser contratado pela instituição, onde permaneceu por cerca de quarenta anos. Dedicou-se primeiramente à fisiologia, área de estudo dos processos de funcionamento dos organismos vivos, e posteriormente à farmacologia e à bioquímica. Chefiou alguns setores de Manguinhos, como o de farmacodinâmica e o de fisiologia, entre 1958 e 1964. Em 1970, junto com outros nove pesquisadores da Fiocruz, teve seus direitos políticos cassados, e passou a trabalhar fora do país. A partir de 1971, tornou-se então professor da Universidade Centro-Oriental, em Barquisimeto, Venezuela, contribuindo para a formação de vários pesquisadores e dirigindo um produtivo laboratório. com os demais colegas cassados, foi readmitido na Fiocruz em 1986, quando reorganizou o Departamento de Fisiologia e Farmacodinâmica do IOC, o

4 Dados e frase do autor extraídos da entrevista publicada em Cientistas do Brasil. São Paulo: SBPC, 1998:45-51. 
qual havia sido extinto na época do Massacre de Manguinhos. Dentre muitos trabalhos realizados, estudou diversos venenos de cobras e isolou uma fração protéica do soro do gambá que tem uma atividade protetora contra eles, ampliando os conhecimentos científicos para o desenvolvimento de soros antiofídicos. Publicou cerca de duzentos trabalhos científicos nas áreas a que se dedicou. Dr. Moussatché foi membro da Academia Brasileira de Ciências, da Academia de Ciências de Nova York, da Federação Mundial de Trabalhadores Científicos e fundador da Sociedade Internacional de Toxicologia e da Sociedade de Biologia do Brasil. Participou do grupo que inspirou a criação da sociedade Brasileira para o Progresso da Ciência (SBPC) e da equipe que planejou a Universidade de Brasília (UnB). 